\title{
Política de indexação em bibliotecas universitárias: estudo diagnóstico e analítico com pesquisa participante ${ }^{1}$
}

\author{
Indexing policy in University libraries: \\ Diagnostic and analytical study \\ with participatory research
}

\author{
Mariângela Spotti Lopes FUJITA² \\ Luciana Beatriz Piovezan dos SANTOS²
}

\section{Resumo}

A indexação tem como função realizar a representação de conteúdos para a recuperação da informação. O êxito dessa mediação depende da orientação de política que considere os requisitos, as variáveis e os elementos característicos da cultura organizacional e o contexto sociocultural de sistemas de representação e recuperação da informação. Como essa operação em bibliotecas é realizada durante a catalogação de assuntos, é necessário investigar a política de indexação das bibliotecas universitárias em seus diferentes estágios com requisitos, variáveis e elementos identificados em manuais ou em documentação institucionalizada sobre a sistematização dessa prática. Com o objetivo de identificar as bibliotecas universitárias que possuem política de indexação e verificar como os catalogadores a aplicam, foram realizados estudo diagnóstico amostral em bibliotecas universitárias das regiões Sul e Sudeste e estudo analítico com pesquisa participante em amostra selecionada. Verificou-se que, embora na maioria das bibliotecas universitárias selecionadas a indexação seja realizada com política específica, ela é feita sem formalização registrada em manual. A averiguação dos requisitos, das variáveis e dos elementos da política de indexação identificaram seus estágios: completo, parcialmente completo e incompleto com deficiências. A minoria das bibliotecas da amostra possui manual de política de indexação, sendo que a análise feita ao longo da pesquisa participante constatou que o processo é realizado pelo catalogador sem o conhecimento ou a aplicação da mesma, reflexo da falta de educação continuada e estudos de avaliação da indexação por meio da recuperação da informação nos catálogos.

Palavras-chave: Bibliotecas universitárias. Indexação. Política de indexação.

\begin{abstract}
The purpose of indexing function is to represent content for the information retrieval. The success of this mediation depends on the indexing policy that takes into account the requirements, variables and the characteristic elements of organizational culture and the socio-cultural context of systems of information representation and retrieval. Considering that indexing in libraries is carried out during subject cataloguing, the different stages of requirements, variables and elements of the indexing policy of university libraries, which are identified in manuals or institutional documents on the systematic practice of indexing, need to be investigated. In order to identify university libraries that have an indexing policy and to verify how the cataloguers apply the indexing policy, we carried out a sampling

\footnotetext{
1 Artigo elaborado a partir do Relatório do Projeto de Pesquisa "Política de Indexação para bibliotecas"do Conselho Nacional de Desenvolvimento Científico eTecnológico (Processo 305648/2009-8)

2 Universidade Estadual Paulista Júlio de Mesquita Filho, Departamento de Ciência da Informação, Programa de Pós-Graduação em Ciência da Informação. Av. Hygino Muzzi Filho, 737, Mirante, 17525-000, Marília, SP, Brasil. Correspondência para/Correspondenceto: M.S.L. FUJITA.E-mail:<fujita@marilia.unesp.br>. Recebido em 4/2/2015, reapresentado em 24/4/2015 e aceito para publicação em 20/5/2015.
} 
diagnostic study at university libraries in the Southern and Southeast Brazilian regions and conducted an analytical study with participatory research of the sample selected. It was found that although indexing in most university libraries follows an indexing policy, it is not described in a manual. When investigating the requirements, variables and elements of the indexing policy, we identified the following: complete, partially complete and incomplete with flaws. Few libraries have a manual on indexing policy and the analysis during participatory research found that the indexing process is performed by the cataloguer without prior knowledge or application of an indexing policy which reflects the lack of continuing education and studies on indexing assessment through information retrieval in the catalogues.

Keywords: University libraries. Indexing. Indexing policy.

\section{Introdução}

A indexação é processo integrante do tratamento temático da informação cuja finalidade é extrair termos representativos do assunto de documentos com o objetivo de representá-los com uso de linguagens específicas para o alcance da recuperação da informação. Como a função da indexação é realizar a representação de conteúdos e permitir a recuperação da informação, nisso reside sua importância estratégica, da qual decorre a estreita relação existente entre seu processo e finalidade (Fujita, 2003). Contudo, o processo por si só não assegura a ampla gama de aspectos, elementos, variáveis, instrumentos, métodos e técnicas que compõem o cenário de um ambiente de sistema de recuperação da informação, que pode ser diferente segundo a cultura de cada comunidade ou domínio de assunto. Mais do que isso, é preciso incluir o contexto sociocultural dos profissionais que atuam nos sistemas de recuperação. A esse conjunto de elementos, variáveis, instrumentos, métodos e técnicas influentes e determinantes denominamos política de indexação.

Essa política, conforme Rubi (2008), existe com o propósito de colaborar para que o objetivo de oferecer a informação desejada ao usuário seja atingido. Dentre as características estruturais dos sistemas de recuperação da informação, deve haver preocupação com uma política que oriente a atuação profissional por meio de decisões orientadas pela cultura organizacional da instituição e contexto sociocultural em que se inserem o sistema de recuperação da informação e a comunidade usuária.

Considera-se, a princípio, que todas as bibliotecas que realizam a indexação como tratamento temático para a construção do catálogo possuem política específica, ainda que com diferentes estágios de formalização devido a um contexto de gestão e tratamento da infor- mação e, principalmente, ao contexto sociocultural do catalogador que realiza o processo. Coube a esta pesquisa identificar a política e, mais do que isso, averiguar quais são os seus estágios de formalização nas bibliotecas universitárias.

\section{Política de indexação em organização e representação da informação}

A organização do conhecimento abrange o tratamento da informação em suas atividades e processos os quais representam os documentos tanto em suas características extrínsecas, ou físicas (tratamento descritivo), quanto em suas características intrínsecas (tratamento temático). A indexação encontra-se entre os processos de análise e representação do conteúdo da informação por meio da identificação e da seleção de conceitos, tendo surgido depois da catalogação de assunto utilizada por bibliotecas. Segundo Alvares Júnior e Saldanha (2013, p.85), "o processo de indexação é, com frequência, abordado como algo relativamente novo dentro do escopo de abordagens que resultaram da demanda por parte da Ciência, consolidada em fins do século XIX, pela representação temática de periódicos".

Hjørland (2003) entende que, em Biblioteconomia e Ciência da Informação, a organização do conhecimento assume o significado de organização da informação contida em registros bibliográficos, quais sejam textos completos, índices de citação ou Internet. Essa organizacão apresenta-se sob duas perspectivas: a cognitiva e a social. A primeira trata de reunir o conhecimento em teorias, sistemas conceituais e conceitos, enquanto a segunda refere-se a sistemas sociais de conhecimento, como organização em disciplinas de estudo, negócios e profissões (Hjørland, 2003).

O objetivo geral em Biblioteconomia e Ciência da Informação, de acordo com Hjørland (2003, p.92), é o 
aperfeiçoamento da "organização do conhecimento em bibliotecas, bases de dados, trabalhos de referência e na Internet" e, para que o mesmo se cumpra, constroem-se métodos e técnicas para o tratamento da informação, tais como a representação, a classificação e a indexação.

De acordo com Guinchat e Menou (1994), esta última é uma forma de descrição que consiste em determinar os conceitos expressos em um documento e representá-los de acordo com os termos correspondentes de uma linguagem documental. A indexação é, portanto, um procedimento de descrição de documentos que atenta para a análise de conteúdo temático e a sua posterior representação com o uso de conceitos provenientes de uma linguagem documental. Essa atividade tem como objetivo principal permitir a interlocução entre usuário e sistema de informação de modo a efetivar a recuperação de dados contidos em documentos presentes em nesses sistemas, bancos de dados e catálogos.

De acordo com Lancaster (2004), as etapas do processo de indexação não ocorrem necessariamente de modo sequencial, podendo o indexador experiente, habituado à tarefa, realizá-las simultaneamente. Ainda que esse processo seja descrito de maneira diversa, em geral, há concordância de que a atividade se dá a partir da realização de três operações básicas comumente identificadas:

- análise: leitura e segmentação do texto para identificação e seleção de conceitos;

- síntese: construção do texto documentário com os conceitos selecionados;

- representação: por meio de linguagens documentárias.

Segundo o World Information System For Science and Technology (1981), deve-se considerar a indexação segundo dois aspectos: quanto processo e quanto a sua finalidade. O primeiro aspecto diz respeito à descrição e identificação de um documento por meio da representação dos conceitos ali presentes; o segundo, refere-se à busca e ao acesso à informação. Com esse propósito, em ambientes de bibliotecas, a representação dos conceitos do documento pode ser usada para identificá-lo, prover pontos de acesso na busca, indicar seu conteúdo ou substituí-lo (Vickery, 1968).
Tendo em vista a função e os objetivos da indexação, a uniformização dos procedimentos que a compõem permite que o trabalho do bibliotecário seja facilitado, resultando em uma seleção de conceitos do documento baseada no perfil do usuário que a biblioteca atende e da instituição que a mantém. Em estudo sobre o processo de indexação e implicações subjacentes na recuperação da informação, conduzido com funcionários de uma biblioteca universitária, os resultados indicam que os aspectos subjetivos se integram às competências individuais para influenciar o tratamento informacional que repercute na recuperação pelos usuários. Por isso, conclui-se que há necessidade do estabelecimento de diretrizes mais precisas para orientar a execução desse processo (Araújo \& Paula, 2014). Essas diretrizes precisam ser orientadas por princípios advindos de uma política de indexação elaborada por consenso entre profissionais atuantes no sistema. Além disso, a mesma deve ser de conhecimento do indexador e estar ao seu alcance para consulta em forma de manuais de rotinas e procedimentos.

As políticas diferem dos manuais no sentido de que as primeiras são bases para que se construam os segundos. Nas palavras de Almeida (2000, p.6), "as políticas ou diretrizes são planos gerais de ação, guias genéricos que estabelecem guias mestras, orientam a tomada de decisão e dão estabilidade à organização". Ainda segundo a autora, os procedimentos são "instrumentos que estabelecem métodos rotineiros de execução de atividades e detalham a maneira exata pela qual uma atividade deve ser realizada e a sequência em que essas rotinas são realizadas" (p.6). Como exemplo, citam-se os manuais de serviço em que se podem incluir os de indexação (Almeida, 2000).

De acordo com Carneiro (1985), as políticas de indexação são guias para a tomada de decisões no planejamento de sistemas de recuperação da informação, de forma a garantir que qualquer informação seja fornecida ao usuário no momento preciso e da maneira mais eficiente e econômica possível. Os objetivos de uma política como essas consistem em definir as variáveis que afetam o desempenho do sistema de informação, estabelecer o critério e os princípios que guiarão a tomada de decisões para tornar esse sistema mais eficiente, a racionalização dos processos e a consistência das ope- 
rações neles envolvidas (Carneiro, 1985). Também pode-se alcançar, com a política de indexação, a harmonização do acesso por assunto em catálogos e bases de dados, tornando explícitas as decisões relativas à indexação para a equipe de trabalho e para os usuários que realizem busca por assunto (Rubi, 2008).

Dessa forma, a construção de dessas políticas apresenta-se como atividade de cunho gerencial, a qual precisa, para seu sucesso, da determinação clara das características e objetivos da biblioteca. O estabelecimento da política de indexação é, portanto, imprescindível em sistemas de recuperação da informação, posto que estabelece seus principais atributos e orienta a tomada de decisões para seu planejamento.

Segundo Carneiro (1985), para o estabelecimento de uma política de indexação levam-se em consideração fatores que são imprescindíveis ao planejamento de qualquer sistema de recuperação da informação: a identificação da organização à qual está vinculado, da clientela de usuários e a determinação dos recursos financeiros, materiais e humanos. O primeiro deles fornecerá dados quanto à área de assunto de interesse do sistema e quanto ao tipo de documento mais importante para essa área, além de dados necessários à determinação de uma política de seleção apropriada, o tipo de informação oferecida, quais sistemas de indexação utilizar e quais níveis de especificidade e exaustividade serão aplicados (Carneiro, 1985). Já a formação do profissional indexador é fator que necessita constar como um dos requisitos da política de indexação, considerando-se seu conhecimento das áreas de assunto, da linguagem documental, do processo em si, bem como sua formação continuada e em serviço (Rubi, 2008).

Para a identificação dos usuários é possível obter informações importantes ao delineamento de uma política de indexação por meio de estudos, como expõe Carneiro em artigo de 1985. Segundo a autora, pode-se obter:

- conhecimento do alcance temático do sistema de informação, definindo os assuntos centrais e periféricos e o(s) nível(is) de tratamento exigido(s); e virtual;

- vocabulário corrente do usuário real, presencial - níveis de exaustividade e especificidade, e
- forma de apresentação dos resultados de busca exigidos pelos usuários.

Considerando a visão de Carneiro (1985) para elaboração de uma política de indexação, devem ser observados os seguintes elementos: cobertura de assuntos, seleção e aquisição de documentos fonte, o processo em si (composto por nível de exaustividade, nível de especificidade, escolha da linguagem e capacidade de revocação e precisão do sistema), estratégia de busca, tempo de resposta do sistema, formato de saída dos dados e avaliação do sistema. Guimarães (2004) amplia a visão de Carneiro (1985), trazendo atualização aos elementos da política de indexação. Dentre suas contribuições, podemos destacar as que se referem à:

- cobertura de assuntos: atualmente deve se preocupar também com a conversão retrospectiva de dados e a compatibilidade de linguagem de indexação entre integrantes de um mesmo sistema cooperativo;

- seleção e aquisição de documentos fonte: levando-se em consideração a evolução tecnológica deve-se preocupar também com a procedência de páginas da Internet e documentos produzidos digitalmente.

O autor ainda aponta dois tópicos levantados por Foskett (1973), e que precisam ser devidamente observados por uma política de indexação:

- capacidade de consulta a esmo (browsing): a usabilidade do sistema, o qual deve revelar de forma fácil e direta, a estrutura temática que o organiza;

- garantia literária (literary warrant) "aspecto que atinge mais diretamente a linguagem de indexação do sistema, de modo a que nela estejam expressas representações de conceitos que efetivamente encontrem lastro no sistema, evitando-se falsas expectativas no usuário" (Guimarães, 2004, p.49).

Olson e Boll (2001) analisam os fatores que determinam a eficiência de um sistema de recuperação da informação que podem ser considerados como decisões gerenciais concernentes à construção de uma política de indexação:

- adequação: refere-se à determinação do assunto do documento e sua adequada tradução em termos de indexação; 
- exaustividade: trata-se do número de conceitos atribuídos ao documento durante sua análise;

- especificidade: aborda o nível hierárquico da representação do assunto durante a fase de tradução dos conceitos;

- consistência: refere-se à representação de conceitos identificados no documento sempre com o uso do mesmo termo de indexação.

Lancaster (2004, p.4) distingue revocação e precisão da seguinte forma: "o termo revocação [é usado] para designar a capacidade [do sistema] de recuperar documentos úteis, e precisão para designar a capacidade de evitar documentos inúteis". Entre exaustividade e revocação existe reciprocidade, assim explicada por Lancaster (2004): quanto mais exaustiva se apresentar, a indexação determinará uma alta revocação e baixa precisão da recuperação. O nível de exaustividade é definido como "extensão com que o conteúdo de uma obra é coberto pelos termos utilizados na indexação" (Lancaster, 2004, p.203).

Por outro lado, quanto mais específica for a seleção de termos, mais precisa será a recuperação, com baixa revocação dos documentos. Compreende-se especificidade como a extensão em que o sistema nos permite a precisão ao especificarmos um documento que estejamos processando (Foskett, 1973). Podemos considerar que a seleção sofre influência da política de indexação do sistema que, baseada no perfil do usuário a que atende, determinará se o termo extraído do documento será mais específico ou mais genérico. Dessa forma, a política de indexação pode ser definida como "um conjunto de procedimentos, materiais, normas e técnicas orientadas por decisões que refletem a prática e princípios teóricos da cultura organizacional de um sistema de informação" (Fujita, 2012, p.22).

A definição desses elementos tem por objetivo equilibrar as respostas do sistema reduzindo os níveis de ruído, ou seja, a recuperação de registros que não são compatíveis com a questão proposta pelo usuário, e de silêncio, a não recuperação de registros pertinentes à questão de busca do usuário ainda que a coleção os contemple.

A política de indexação é dinâmica e deve atentar para a sua própria atualização, visto que as condições em que é instaurada se alteram. Para tomar conhecimento disso, existe o processo de avaliação. Este, segundo Lancaster e Gallup (1973), deve abranger o estabelecimento do alcance e propósito do programa de avaliação (decidir o que vai ser apreciado), planejamento do processo, análise e interpretação dos resultados e modificações no sistema de acordo com os resultados obtidos. Conforme Almeida (2000, p.15), a avaliação “[...] não deve ser uma ocorrência isolada, um evento, mas um processo contínuo por meio dos quais programas e serviços sejam examinados, isolada ou conjuntamente, a fim de se garantir que objetivos e metas estejam sendo cumpridos".

Portanto, segundo a literatura (Carneiro, 1985; Lancaster, 1996; Guimarães, 2004; Gil Leiva, 2008; Fujita, 2012), a política de indexação reúne elementos, variáveis, procedimentos, instrumentos e métodos de avaliação definidos pela instituição a que se destina em função de requisitos de organização, clientela, recursos financeiros, materiais e humanos. Essa política terá como elementos: cobertura de assuntos ou domínios de especialidade, documentos ou recursos de informação, estratégia de busca, o processo de indexação e a avaliação. O processo de indexação como elemento essencial da política é, por sua vez, influenciado pelas variáveis da recuperação da informação: escolha da linguagem, exaustividade, especificidade, revocação e precisão.

Com isso, pode-se definir uma política de indexação para um sistema de recuperação da informação com requisitos, variáveis e elementos, elaborando um manual da seguinte forma:

\section{Parte 1: Orientações Gerais}

- Requisitos do sistema de recuperação da informação;

- Variáveis da indexação e da recuperação da informação.

Parte 2: Orientações Específicas

- O processo de indexação (elemento);

- A linguagem de indexação (variável);

- Avaliação da Indexação (elemento).

Tendo em vista a complexidade da definição de uma política desse tipo com orientações gerais e específicas aos profissionais, aponta-se como problema a dificuldade em identificar os processos e condutas da 
atividade de indexação em bibliotecas, considerando-se as distinções entre requisitos, variáveis e elementos e sua composição para a orientação de tal política.

Considerando-se as bases teóricas que fundamentaram o desenvolvimento deste estudo, especialmente o quadro conceitual sobre política de indexação, segue o esclarecimento do quadro metodológico com base em estudo diagnóstico e analítico composto de aplicação de questionário e pesquisa com observação participante que incluiu o uso da técnica introspectiva de protocolo verbal individual. Na sequência, são demonstrados os resultados obtidos, com destaque para a identificação dos estágios de política de indexação em que se encontram as bibliotecas universitárias, e considerações finais quanto à pesquisa realizada.

\section{Procedimentos metodológicos}

O estudo diagnóstico e analítico foi composto por duas etapas de coleta de dados 3 . A primeira constou de aplicação de questionário sobre política de indexação. A análise dos dados obtidos resultou na identificação de bibliotecas com estágio mais completo de política de indexação para realização da segunda etapa, o estudo analítico, por meio de pesquisa participante com visitas para observação de procedimentos da documentação (manuais ou rotinas de serviço) e entrevistas com os catalogadores e funcionários das bibliotecas para contextualizar e complementar as informações coletadas.

\section{Estudo diagnóstico com aplicação de questionário}

O questionário, elaborado por Fujita (2010) para coleta de dados, tem por objetivo "verificar se os pro- fissionais fazem indexação e se adotam uma política de indexação e manual de indexação com base nos estudos teóricos e metodológicos sobre indexação, política de indexação e experiências de elaboração de política de indexação e manuais de indexação" (Fujita, 2010, p.31).

Para alcance do objetivo a que se propõe, o questionário (Anexo A) apresenta 20 questões, divididas em 5 seções (Quadro 1).

Em pesquisa realizada nas Bibliotecas de Instituições Brasileiras de Ensino Superior (BIBES), base de dados organizada pela Comissão Brasileira de Bibliotecas Universitárias (CBBU) que reúne informações sobre as bibliotecas universitárias brasileiras, constatou-se que as regiões Sul e Sudeste do Brasil possuem 724 bibliotecas universitárias cadastradas, sendo 263 na primeira e 461 na segunda. Foram adotados os seguintes critérios para seleção das bibliotecas onde o questionário seria aplicado: bibliotecas universitárias localizadas nas regiões Sul e Sudeste do Brasil que possuem acervo mínimo de 150 mil exemplares catalogados e dispõem de catálogo de acesso on line. Obteve-se o total de 102 bibliotecas que atendem a esses critérios, o que corresponde a 14\% do total das duas regiões pesquisadas. A aplicação do questionário foi realizada por envio eletrônico, utilizando-se, como instrumentos, o correio eletrônico (e-mail) e a ferramenta de questionário online survey monkey.

\section{Estudo analítico com pesquisa participantes}

Tendo em vista a sistematização da coleta de dados, elaborou-se um roteiro para realização das visitas de observação participante, de modo que norteasse sua condução como relatado a seguir:

Quadro 1. Estrutura do questionário de identificação de política de indexação em bibliotecas.

\begin{tabular}{lcc}
\hline Seções do questionário & Política de indexação & Questões \\
\hline Dados gerais da instituição. & Requisitos & $1,2,3,4,5,6$ \\
Prática da indexação ou catalogação de assuntos. & Elementos & $7,7.1,8,9,10$ \\
Qualidades da indexação. & Variáveis & $11,12,13,14,15$ \\
Ferramentas para a indexação ou catalogação de assuntos. & Variáveis & $16,17,18$ \\
Avaliação da indexação ou catalogação de assuntos. & Elementos & 19,20 \\
\hline
\end{tabular}

Fonte: Elaborado pelas autoras (2014)

\footnotetext{
$\overline{3}$ Os dados foram coletados no período de 2010 a 2012 em bibliotecas da região sul e sudeste no âmbito do projeto de pesquisa intitulado "Política de indexação em bibliotecas", coordenado por Mariângela Spotti Lopes Fujita com bolsa Pq/CNPq nível 1C, financiada pelo Conselho Nacional de Desenvolvimento Científico e Tecnológico.
} 
1) Primeiro passo: primeiras observações - conversa informal com funcionários. Coleta de manuais e documentos correlatos para análise.

2) Segundo passo: observação do processo de catalogação de assunto de livros com Protocolo Verbal Individual.

3) Terceiro passo: entrevista retrospectiva com o catalogador para aprofundar e discutir a prática de indexação na catalogação e na execução da política de indexação com perguntas elaboradas a partir das respostas obtidas com o questionário aplicado.

4) Coleta de informações com funcionários e estagiários através das perguntas:

- Recebeu algum treinamento ao iniciar a função?

- Teve contato com algum manual ou roteiro de procedimentos?

- Conhece a missão/visão/valores da instituição?

- Como vê a atividade de catalogação de assuntos/indexação na instituição?

A pesquisa participante teve como foco a realização da indexação e a execução de sua política nas bibliotecas observadas como forma de interação com a realidade profissional. A análise dos dados coletados busca evidenciar a forma como os profissionais se relacionam com a atividade de trabalho e como a política de indexação se reflete nessa relação.

Com os Protocolos Verbais (PV), realizou-se a transcrição integral das falas dos sujeitos visando a análise em categorias utilizadas na entrevista retrospectiva com - catalogador para aprofundar e discutir a prática de indexação e a execução de sua política. Após a realização das visitas de observação, foram redigidos relatórios de observação baseados na interação verbal dos observadores com a equipe.

\section{Resultados e Discussão}

O estudo diagnóstico e analítico propiciou observar, por meio de amostras, o ambiente de bibliotecas universitárias no intuito de compreender o contexto da política de indexação e a forma como esta influencia a prática de indexação em tais ambiências profissionais. $\mathrm{O}$ estudo diagnóstico teve seus resultados obtidos a partir da análise dos questionários e, para o analítico, foram selecionadas quatro bibliotecas universitárias.

\section{Estudo diagnóstico da política de indexação em bibliotecas universitárias}

Foram obtidos 46 questionários respondidos dentre os 102 enviados, sendo 18 de bibliotecas da região Sul do Brasil e 21 da Sudeste. Em 7 deles, não constava a identificação da biblioteca, o que inviabilizou a identificação do estado e, por isso, foram desprezados na análise (Quadro 2).

Conforme Quadro 1, a análise dos dados coletados nos 39 questionários pautou-se pelas seções dos mesmos, a saber:

a) Dados gerais (histórico da instituição, áreas de assunto da coleção, quantidade de profissionais na biblioteca, quantidade de profissionais que realizam indexação, educação continuada do indexador).

Constatou-se que em 36 das 39 bibliotecas consultadas o processo de indexação é manual e realizado por profissionais graduados em biblioteconomia. Em três delas, a atividade é exercida por auxiliares de biblioteca não graduados, sendo que apenas em uma delas há orientação do bibliotecário responsável para a realização da indexação. Uma biblioteca realiza a atividade de forma mista (funcionários graduados e não graduados em biblioteconomia) e há uma outra que não dispõe de nenhum bibliotecário para a atividade.

Considera-se importante destacar que há uma média de um profissional dedicado à tarefa de indexa-

Quadro 2. Locais de origem dos questionários respondidos.

\begin{tabular}{llc}
\hline Regiões & \multicolumn{1}{c}{ Estados } & Bibliotecas (n) \\
\hline Sul & Rio Grande do Sul & 11 \\
& Santa Catarina & 2 \\
& Paraná & 5 \\
Sudeste & São Paulo & 17 \\
& Espírito Santo & 2 \\
& Minas Gerais & 1 \\
Não identificada & Rio de Janeiro & 1 \\
\hline Total & 7 & 7 \\
\hline
\end{tabular}

Fonte: Elaborado pelas autoras (2014). 
ção/catalogação de assunto por biblioteca. Ainda assim, nota-se que em 22 delas há entre 0 e 3 profissionais dedicados a tal atividade. As demais frequências encontradas ficaram assim distribuídas: em 13 bibliotecas verificou-se a presença de 4 à 6 bibliotecários dedicados à tarefa de indexação; em três, há entre 7 e 14 bibliotecários; uma instituição relatou a presença de 40 bibliotecários destinados à indexação e uma outra não respondeu à questão.

Em apenas três instituições foi relatado que a indexação está a cargo de pessoal não graduado. Embora esse percentual seja baixo, tal realidade não corresponde ao ideal. Tendo em vista a complexidade da tarefa de indexação e sua importância para a recuperação da informação, é desejável que seja realizada por profissionais que receberam formação quanto a, por exemplo, estrutura textual referente a diferentes tipologias encontradas no ambiente acadêmico, quanto aos instrumentos de apoio à realização da indexação, assim como quanto à necessidade e busca por informação por parte do usuário.

Os dados obtidos mostram que em 14 bibliotecas há oferta de treinamento para o bibliotecário ao iniciar no desempenho da função, evidenciando que essas instituições consideram que a formação inicial é suficiente para a realização da indexação, já que não são oferecidos cursos de treinamento para ingresso do profissional na atividade. Dados semelhantes são observados quanto à oferta de formação continuada para os profissionais. Em 24 bibliotecas, não há oferta de cursos de aperfeiçoamento e atualização profissional, enquanto em 15 há essa possibilidade, embora, em quatro delas seja necessário que o profissional solicite sua participação.

b) Prática de indexação ou catalogação de assunto (fonte de registros bibliográficos para conversão retrospectiva, regulamentação de política de indexação, manual de indexação, auxílio automático ou semiautomático na indexação).

Quanto à prática de indexação ou catalogação de assunto, 33 instituições relataram que realizam a conversão retrospectiva de registros bibliográficos com as seguintes fontes para consulta de dados:

$$
\begin{aligned}
& \text { - Fundação Biblioteca Nacional, } 20 \text { bibliotecas } \\
& \text { - Library of Congress, } 16 \\
& \text { - Rede Bibliodata, } 9
\end{aligned}
$$

- Rede Pergamum, 7

- Vocabulário Controlado USP, 6

- Biblioteca Virtual de Saúde (BIREME), 4

- Universidade Estadual Paulista (Unesp), 3

- British Library, 3

- Universidade Estadual de Campinas (Unicamp), 3

- Online Computer Library Center (OCLC), 2.

Verificou-se que 21 bibliotecas da amostra possuem alguma ferramenta de auxílio automático ao catalogador de modo a garantir a consistência na representação da informação. Averiguou-se que 33 das bibliotecas consultadas por esta pesquisa realizam conversão retrospectiva de registros bibliográficos para compor seus catálogos. Essa prática trouxe benefícios à representação descritiva em bibliotecas, porém, no que tange à representação temática, faz-se necessário que os dados obtidos dessa forma sejam avaliados pelo bibliotecário dentro de parâmetros institucionalizados para que se garanta a convergência com as características da biblioteca e de seu público no catálogo.

Quanto à existência de política de indexação e manual de indexação, 13 das bibliotecas afirmaram que possuem política de indexação disponível para consulta pela equipe de trabalho e 22 afirmaram que possuem manual de rotinas para a realização do tratamento técnico da informação, o que demonstra a existência de preocupação de tais instituições com a formalização das práticas adotadas por seus profissionais.

c) Qualidades da indexação (grau de especificidade, quantidade de termos por documento, tempo para indexação, uso de norma para a indexação, documentação da política de indexação).

Como 23 bibliotecas não possuem determinação para a especificidade da indexação e 23 não possuem critério para a exaustividade do processo, a confiabilidade do processo de indexação realizado fica comprometida. Em relação à adoção de regulamentações para a realização do processo de indexação, 19 bibliotecas afirmaram que seguem as determinações de alguma norma, nacional ou internacional.

d) Ferramentas para a indexação ou catalogação de assuntos (sistema de validação automática de termos/ 
assuntos, uso de linguagem natural, linguagens de indexação utilizadas, participação em projetos de interoperabilidade de vocabulários controlados).

Com relação às ferramentas disponíveis aos profissionais, constatou-se que 26 bibliotecas não possuem instrumento para validação automática de termos atribuídos. Em relação à linguagem documentária, 20 delas relataram que não possuem em seus catálogos assuntos representados por palavras em linguagem natural.

As linguagens documentais utilizadas são:

- Library of Congress Subject Headings (LCSH), 8 bibliotecas

- Fundação Biblioteca Nacional, 8

- Lista de Cabeçalho de Assunto da Rede Bibliodata (LCARB), 6

\footnotetext{
- Descritores em Ciências da Saúde (DeCS), 3

- Rede Pergamum, 3

- Vocabulário controlado USP, 2
}

- Tesauro Spines, 2

- Linguagem Unesp, 2

- Vocabulário de construção própria, 2

Das bibliotecas pesquisadas, 34 relataram que nunca participaram de projetos de interoperabilidade de linguagens documentais.

e) Avaliação da indexação ou catalogação de assuntos (ensaio para avaliação periódica da prática de indexação, relatórios de avaliação publicados).

Quanto à avaliação da indexação, constatou-se que 37 bibliotecas afirmaram nunca terem realizado ensaios de avaliação da indexação/catalogação de assuntos. O estudo diagnóstico e analítico realizado com amostras de bibliotecas universitárias, confirmou, principalmente, que o tratamento temático de conteúdo ou indexação é realizado com política de indexação, mesmo considerando que não exista uma formalização registrada e utilizada pelos catalogadores bibliotecários.

A averiguação de requisitos, variáveis e elementos da política de indexação confirmou que estes compo-

Quadro 3. Estágios da política de indexação em bibliotecas universitárias.

\begin{tabular}{|c|c|c|c|}
\hline $\begin{array}{l}\text { Estágios/Componentes da } \\
\text { política de indexação }\end{array}$ & $\begin{array}{l}\text { Completo } \\
\text { (4 bibliotecas) }\end{array}$ & $\begin{array}{l}\text { Parcialmente completo } \\
\text { (27 bibliotecas) }\end{array}$ & $\begin{array}{l}\text { Incompleto com deficiências } \\
\text { (8 bibliotecas) }\end{array}$ \\
\hline $\begin{array}{l}\text { Requisitos (Seção de Dados Ge- } \\
\text { rais) }\end{array}$ & $\begin{array}{l}2 \text { a } 3 \text { bibliotecários fazendo a } \\
\text { indexação e que recebem edu- } \\
\text { cação continuada mais de } 2 \text { ve- } \\
\text { zes ao ano. }\end{array}$ & $\begin{array}{l}\text { Um bibliotecário fazendo a indexação } \\
\text { e que recebe educação continuada } \\
\text { quando solicita. }\end{array}$ & $\begin{array}{l}\text { Um auxiliar de bibliotecário, } \\
\text { su-pervisionado por profis- } \\
\text { sional, fazendo a indexação e } \\
\text { que recebeformação em serviço. }\end{array}$ \\
\hline $\begin{array}{l}\text { Variáveis (Seções de qualidades } \\
\text { de indexação e de ferramentas } \\
\text { para indexação) }\end{array}$ & $\begin{array}{l}\text { Definição de grau de especifici- } \\
\text { dade e quantidade de termos, } \\
\text { sistema de validação automática } \\
\text { de termos atribuídos, uso de lin- } \\
\text { guagem de indexação sem lin- } \\
\text { guagem natural, realização de } \\
\text { projetos de interoperabilidade } \\
\text { de linguagens documentais. }\end{array}$ & $\begin{array}{l}\text { Sem definição de grau de especifi- } \\
\text { cidade, mas com definição de quanti- } \\
\text { dade de termos, sistema de validação } \\
\text { automática de termos atribuídos, uso } \\
\text { de linguagem de indexação e de lin- } \\
\text { guagem natural. }\end{array}$ & $\begin{array}{l}\text { Sem definição de grau de es- } \\
\text { pecificidade, mas com defini- } \\
\text { ção de quantidade de termos, } \\
\text { sistema de validação automá- } \\
\text { tica de termos atribuídos, uso } \\
\text { de linguagem natural com uso } \\
\text { de vocabulário próprio. }\end{array}$ \\
\hline $\begin{array}{l}\text { Elementos (Seções de prática de } \\
\text { indexação e de avaliação da } \\
\text { indexação) }\end{array}$ & $\begin{array}{l}2 \text { ou } 3 \text { fontes confiáveis de con- } \\
\text { versão retrospectiva, ferramenta } \\
\text { de auxílio automático ao indexa- } \\
\text { dor para consistência na repre- } \\
\text { sentação da informação, manual } \\
\text { de indexação com política de } \\
\text { indexação regulamentada, nor- } \\
\text { ma para o processo de indexa- } \\
\text { ção, realização de ensaio de ava- } \\
\text { liação da indexação. }\end{array}$ & $\begin{array}{l}\text { Uma fonte confiável de conversão re- } \\
\text { trospectiva, ferramenta de auxílio } \\
\text { automático ao indexador para consis- } \\
\text { tência na representação da infor- } \\
\text { mação, manual de rotinas para a reali- } \\
\text { zação do tratamento técnico da infor- } \\
\text { mação, realiza processo de indexação } \\
\text { sem norma, não realização de ensaio } \\
\text { de avaliação da indexação. }\end{array}$ & $\begin{array}{l}\text { Sem fonte confiável de conver- } \\
\text { são retrospectiva, não tem } \\
\text { ferramenta de auxílio automá- } \\
\text { tico ao indexador para consis- } \\
\text { tência na representação da } \\
\text { informação, manual de rotinas } \\
\text { para a realização do tratamen- } \\
\text { to técnico da informação, reali- } \\
\text { za processo de indexação sem } \\
\text { norma, não realização de en- } \\
\text { saio de avaliação da indexação. }\end{array}$ \\
\hline
\end{tabular}

Fonte: Elaborado pelas autoras (2014). 
nentes da política estão presentes nas bibliotecas, como demonstram os resultados do estudo diagnóstico. A deter-minação de estágios de formalização da política de indexação - completo, parcialmente completo e incompleto com deficiências -, realizada a partir dos resultados da tabulação e análise dos dados dos questionários respondidos, identificou a seguinte situação (Quadro 3).

Em análise do quadro acima é possível afirmar que a maioria das bibliotecas da amostra apresenta política de indexação completa e parcialmente completa. Poucas possuem manual de indexação com política regulamentada com norma para o processo. Para as bibliotecas que possuem manual de rotinas sem a formalização da política de indexação, considera-se que falta apenas transformá-lo em um manual mais completo, contendo requisitos, variáveis e elementos após discussão e negociação entre todos os envolvidos: gestores, catalogadores e usuários. Isso seria um benefício à representação e recuperação da informação em catálogos de bibliotecas universitárias. Entretanto, as bibliotecas da amostra que se encontram no estágio incompleto apresentam deficiências estruturais que impedem o avanço e o aprimoramento da representação e recuperação e, por isso, necessitariam resolver, principalmente, a deficiência mais grave que é o fato do trabalho da indexação ser realizado por auxiliares sem formação inicial e impossibilitados de receber a formação continuada. Outros problemas importantes a serem resolvidos são o uso de fontes não confiáveis na conversão retrospectiva e a falta do auxílio automático ao indexador para consistência na representação. A proposta de averiguação desses estágios foi distinguir as diferentes situações de existência da política de indexação e, sobretudo, indicar as condições ideais e como alcançá-las.

\section{Estudo analítico com pesquisa participante}

Para a realização da observação participante foram selecionadas as quatro bibliotecas que possuem estágio completo de política de indexação no diagnóstico apresentado e que tinham manual com política de indexação para uso na biblioteca. Apresentamos a seguir a caracterização das instituições como forma de contextualizar as análises realizadas (Quadro 4).

As bibliotecas, denominadas nesta pesquisa de Bibliotecas A, B, C e D, estão localizadas no estado de São Paulo; uma delas situa-se na capital e três no interior. Da mesma maneira, três das instituições selecionadas compõem Instituições de Ensino Superior (IES) de caráter público e uma, privado.

Quadro 4. Características das bibliotecas universitárias selecionadas.

\begin{tabular}{|c|c|c|c|c|}
\hline Bibliotecas & Biblioteca A & Biblioteca B & Biblioteca C & Biblioteca D \\
\hline Natureza da IES & Pública & Privada & Pública & Pública \\
\hline Acervo & $\begin{array}{l}90 \text { mil livros, } 2700 \text { teses e } \\
\text { dissertações, } 2377 \text { títulos } \\
\text { de periódicos. }\end{array}$ & $\begin{array}{l}\text { Aproximadamente } 255 \text { mil } \\
\text { itens entre livros, periódi- } \\
\text { cos, obras de referências, } \\
\text { mapas, gravuras, slides, } \\
\text { DVDs, CDs e fitas de vídeo. }\end{array}$ & $\begin{array}{l}87246 \text { livros, } 2793 \text { teses e } \\
\text { dissertações, } 1272 \text { títulos } \\
\text { de periódicos. }\end{array}$ & $\begin{array}{l}170 \text { mil títulos existentes, } \\
\text { distribuídos entre livros, teses, } \\
\text { periódicos e multimeios. }\end{array}$ \\
\hline Equipe & $\begin{array}{l}6 \text { bibliotecários, } \\
7 \text { auxiliares de biblioteca. }\end{array}$ & $\begin{array}{l}3 \text { bibliotecários e } 24 \text { cola- } \\
\text { boradores da Universi- } \\
\text { dade. }\end{array}$ & $\begin{array}{l}10 \text { bibliotecários, } 10 \text { auxi- } \\
\text { liares de biblioteca, } 1 \text { as- } \\
\text { sistente administrativo, } 1 \\
\text { técnico de informática. }\end{array}$ & $\begin{array}{l}9 \text { bibliotecários, } 6 \text { auxiliares } \\
\text { de bibliotecas, } 9 \text { técnicos, } \\
4 \text { estagiários. }\end{array}$ \\
\hline Cobertura de assuntos & $\begin{array}{l}\text { Ciências Humanas, Ciên- } \\
\text { cias Sociais Aplicadas, Le- } \\
\text { tras, Linguística, Artes, } \\
\text { Ciências Biológicas. }\end{array}$ & $\begin{array}{l}\text { Ciências Exatas, Ciências da } \\
\text { Saúde, Ciências Humanas } \\
\text { e Ciências Sociais Apli- } \\
\text { cadas. }\end{array}$ & $\begin{array}{l}\text { Arquitetura, Artes, Comu- } \\
\text { nicação, Ciências e En- } \\
\text { genharia. }\end{array}$ & Economia, Administração. \\
\hline Indexação & Manual & Manual & Manual & Manual \\
\hline Catalogadores & 2 & 3 & 5 & 4 \\
\hline
\end{tabular}

Fonte: Elaborado pelas autoras (2014)

Nota: IES: Instituições de Ensino Superior. 
Dentre as quatro bibliotecas selecionadas, duas são componentes da rede de bibliotecas de uma mesma universidade. Nomeadas como Biblioteca A e Biblioteca C. Tais locais estão ligados a faculdades diferentes e situam-se, do mesmo modo, em cidades distintas do estado. As duas bibliotecas foram observadas com um intervalo temporal, de modo que a primeira foi analisada em um período no qual a política de indexação institucional encontrava-se em fase de determinação e testes, e a segunda a política encontrava-se definida e implantada. Dessa forma, os resultados obtidos seguiram o roteiro da pesquisa participante e são descritos pela análise da documentação, observação do processo de catalogação de assuntos de livros e entrevista retrospectiva.

\section{Documentação do processo de indexação: o manual de indexação}

Analisando o manual de serviços da Biblioteca A, constatou-se que o mesmo não apresenta indicações de como proceder à realização da indexação, porém indica que é necessária a consulta ao manual de normas e procedimentos para atribuição de cabeçalhos de assunto da Rede Bibliodata. Da mesma forma como ocorre com a realização da catalogação, o manual de procedimentos orienta à consulta do padrão de catalogação da instituição. Quanto às outras atividades da seção, o manual apresenta a ordem com que devem ser realizadas e sua descrição, constituindo-se em elemento de aprendizagem organizacional. Em contrapartida, verificou-se que o material é desconhecido por parte dos membros da equipe de estagiários e de funcionários novos, que seriam os mais interessados em sua utilização.

Quanto à especificidade, o manual indica que se utilizem termos mais específicos nas áreas em que o vocabulário os oferece, e termos gerais nas áreas em que isso não acontece, optando-se, quando possível, pela indexação mais específica possível. Para a exaustividade, determina-se o uso de 3 a 12 termos descritores para a indexação. Não há determinação ou estudos de tempo gasto na realização da tarefa. A instituição utiliza a norma ABNT 12.676 como parâmetro para a realização do processo, apoiando-se nos questionamentos ao documento que a norma indica.

A Biblioteca B possui manual de procedimentos disponível apenas para a equipe interna, não tendo sido disponibilizado ao observador. Constatamos, entretanto, que o mesmo trata apenas da catalogação descritiva. A instituição possui diretrizes para tratamento da informação temática contida no manual de uso do vocabulário controlado de construção própria. Apesar de ter informado no questionário a existência de uma política de indexação, na observação participante isso não pôde ser confirmado. Há determinação de diretrizes para tratamento de diferentes tipologias de documentos, sendo realizada anualmente uma avaliação da documentação. Não foi observada a definição de especificidade para a realização da indexação. Quanto à exaustividade da mesma, a instituição relatou que determina a atribuição média de três a cinco termos para cada registro, utilizando o Código de Catalogação Anglo Americano (AACR2) como instrumento de padronização de seus procedimentos.

O manual da Biblioteca C indica que a indexação tem sido realizada pelo bibliotecário catalogador da unidade, prevendo a necessidade de oferta de formação a esse tipo de profissional para execução da rotina tanto no que se refere às decisões tomadas na política de indexação e na utilização do manual dela derivado, quanto no uso da Linguagem documental da instituição. A exaustividade está determinada pela quantidade de 3 a 12 termos para representar os documentos. Quanto à especificidade, é indicada a realização da indexação no nível mais específico. O manual também determina claramente como deve ser feita a análise do documento, indicando partes do texto em que a leitura deve se deter (prefácio, sumário, introdução e metodologia), assim como apresentando questionamentos ao texto que, combinados com a leitura das partes indicadas do documento, têm por objetivo facilitar a identificação de conceitos.

Como forma de garantir a consistência do catálogo, o manual da instituição indica que o catalogador deve seguir a metodologia de indexação institucionalizada, cujo procedimento se encontra em diretrizes do manual. Tais diretrizes permitem inferir a preocupação com a redução da subjetividade inerente à essa metodologia. A tentativa de compatibilizar não apenas a linguagem e o sistema tecnológico, mas também os métodos para realização dessa tarefa, pode imprimir mais objetividade na representação do conhecimento ao 
caminhar na direção da padronização, ao menos no que se refere ao âmbito profissional. Observou-se, na análise do manual, que a instituição pretende realizar procedimentos de avaliação da indexação, tendo sido definido que os mesmos deverão ser realizados com periodicidade anual, porém os métodos de avaliação não são descritos no manual.

A Biblioteca D possui política de indexação documentada e manual de procedimentos disponível na página institucional na Web aos funcionários. Utilizam vocabulário controlado, de construção própria, havendo um grupo de trabalho responsável pela sua avaliação e atualização. Quanto à especificidade, a instituição relatou que indica a indexação no nível mais específico possível, porém não há estabelecimento de parâmetros para a exaustividade. A instituição relatou não seguir a determinação de nenhuma norma para a realização da indexação, assim como não realiza estudos do tempo gasto nesse procedimento.

A análise do manual de indexação dessa instituição permitiu constatar que a mesma é vista como um procedimento que requer pessoal capacitado, uso de um vocabulário adequado para a representação do conhecimento e uma política explícita. Apesar de não definir claramente o quesito de exaustividade, apresenta diretrizes de como evitar assinalar número excessivo de descritores.

\section{Observação do processo de indexação/catalogação de assunto de livros}

Foi observada na Biblioteca $A$ a execução da catalogação de assunto de uma tese e de um livro por dois profissionais distintos, cada um com tipologia diferente. Não houve padronização dos procedimentos de análise dos documentos, mas padrões individuais entre os profissionais que realizaram a tarefa.

Informações contraditórias foram reveladas pelos estagiários, quanto ao fato de que realizam a compatibilização dos termos de indexação recuperados por meio de importação de dados. Tais estagiários, alunos de graduação em biblioteconomia, não recebem treinamento da biblioteca para a realização da indexação, diferentemente do que foi constatado quanto à catalogação.
Torna-se evidente, na comparação do procedimento de tratamento temático realizado por dois profissionais diferentes, a necessidade da existência de diretrizes que padronizem a atividade. Ressalvadas as diferenças de tipologias documentais, o procedimento apresentou distinções consideráveis. Se, por um lado, a exploração textual dos trabalhos acadêmicos para indexação foi pouco satisfatória, fator possivelmente causador da dificuldade apresentada pelo profissional na compreensão do assunto tratado, por outro, existe preocupacão, por parte do profissional, com a compreensão do assunto abordado no livro na análise do documento realizada para o tratamento desses materiais.

De modo geral, a observação participante permitiu verificar que os profissionais responsáveis pela realização da catalogação de assuntos na instituição possuem grande domínio das habilidades técnicas e das ferramentas para a realização da atividade, embora, em contrapartida, não tenham o hábito de questionar essas técnicas e ferramentas, algo que se torna essencial para a evolução do fazer profissional.

Durante a observação participante na Biblioteca $B$, verificou-se que, embora tenha afirmado no questionário possuir política de indexação disponível para a equipe, tendo sido assim considerada apta a participar da pesquisa por atender a todos os critérios de seleção, a instituição não possui política de indexação documentada, apenas procedimentos padronizados para realização da tarefa aceitos tacitamente pela equipe. Foi relatado ao observador, entretanto, o interesse em documentar tais procedimentos e decisões tomadas pelos funcionários.

Para a representação temática é utilizado vocabulário de construção própria, no qual podem ser inseridos termos novos de acordo com a necessidade, assim como termos em linguagem natural, na forma de vocábulos livres para representar assuntos pouco frequentes no acervo. Não participam de projetos de interoperabilidade de vocabulários controlados e foi a única instituição que relatou não possuir nenhum tipo de auxílio ou correção automática para a inserção de informações em seus registros bibliográficos como garantia de consistência do catálogo.

Na Biblioteca C existem seis profissionais dedicados às tarefas de tratamento técnico dos recursos de 
informação e é oferecida à equipe treinamento continuado para a realização de tais atividades. Foi constatado que, embora a instituição possua um manual recente e desenvolvido conjuntamente com a política de indexação, esse não foi consultado pelo indexador no momento da realização da tarefa proposta pelo observador. Quando se fez a análise do manual, foi constatado que a tarefa realizada estava em concordância com a forma proposta pelo manual. Pode-se inferir, desse modo, que mesmo sendo recente, a política de indexação encontrava-se internalizada pelo profissional observado nessa instituição, fazendo parte de seu fazer profissional cotidiano.

Durante o procedimento de catalogação de assunto de livro, o funcionário relatou que realiza a exploração da estrutura textual de acordo com a dificuldade em identificar termos. A sequência observada na exploração da estrutura textual foi análise do sumário, introdução e índice. Afirmou realizar correção dos termos, utilizando uma ferramenta de verificação no vocabulário controlado de construção própria e adotado pela instituição, o qual se encontra integrado ao sistema de gerenciamento do catálogo. Relatou que é permitida apenas a utilização desse vocabulário controlado para representação do acervo.

A exploração textual do documento, embora tenha sido sucinta, permitiu a compreensão do assunto tratado sem que o profissional apresentasse dificuldade. Na comparação do procedimento observado com o manual de indexação da instituição, foi possível verificar que a exploração textual foi direcionada pelo manual, tornando-a mais objetiva e de fácil realização.

A observação participante realizada na Biblioteca $D$ revelou que a política e o manual de indexação da instituição eram desconhecidos por parte da equipe. Foi relatado no questionário que a instituição não possuía um documento formal para tais questões, porém havia sido localizado pelo observador na página Web da instituição um documento contendo sua política de indexação.

Na comparação do procedimento de indexação/ catalogação de assunto, verificou-se a existência de padrões individuais de tratamento documental. Para o tratamento de teses e dissertações, o profissional realizou a análise do resumo e introdução do documento; já para o processamento do livro, foi realizada a leitura da introdução, índice, trechos dos capítulos, apresentação e sumário. Pôde-se perceber a discrepância da análise indicada no manual de indexação com a efetivamente realizada pelo profissional, pois no manual é indicada apenas a leitura da introdução do documento para identificar o seu núcleo informativo. Já a exploração de estrutura textual do procedimento, observado para a indexação de tese, foi feita com a leitura do resumo e da introdução, enquanto para a indexação de livros foi feita a leitura da introdução, índice, trechos dos capítulos, apresentação e sumário. A complementação do manual, no que tange à exploração da estrutura textual, deve conter outras partes do documento que contêm informação relevante para a indexação como forma de aprimorar a definição dos parâmetros de exaustividade e especificidade na determinação de descritores.

Foi interessante constatar que existe uma ferramenta atrelada ao vocabulário controlado da instituição por meio da integração do banco de dados bibliográficos com as listas de autoridades que funcionam como garantia de correção para inclusão de termos de indexação. Verificou-se também que a instituição autoriza apenas o uso do vocabulário controlado para inclusão de termos de indexação, não sendo permitida a utilização de palavras em linguagem natural.

A indexação na Biblioteca D é relatada pela equipe observada e pelo manual de indexação como um procedimento importante, por figurar como responsável pela forma mais típica de recuperação por parte da comunidade usuária, sendo considerada um requisito de qualidade para os catálogos disponíveis on line. Vale observar que a confiabilidade da equipe em seu vocabulário faz com que a realização de procedimentos de avaliação da indexação seja considerada desnecessária, porque o processo, nessa biblioteca, é feito tendo por base a linguagem documental. O uso constante de uma mesma linguagem, todavia, pode vir a condicionar a realização da análise por parte do catalogador por levá-lo a ignorar determinados conceitos identificados, considerando que a linguagem em que será feita a tradução não os contempla. 


\section{Entrevista retrospectiva com o catalogador}

Após o processo de catalogação de livro, o foco da observação voltou-se para a solução de dúvidas que haviam surgido durante a visita, recorrendo-se à entrevista retrospectiva como forma de aprofundar as discussões sobre a prática de indexação/catalogação de assunto e a política de indexação. Questionado sobre a atribuição de termos em outro idioma diverso do português, o catalogador da Biblioteca A explicou que há a indicação, para tratamento de trabalhos acadêmicos, de que sejam usados os mesmos termos assinalados pelo autor como palavras-chave, traduzidos para o idioma inglês. Ao realizar essa atribuição sem consulta à linguagem documental, considera-se que é feita sem a definição de critérios de consistência ao conjunto de representações temáticas do catálogo. Uma solução para tal questão poderia ser a adoção da tradução do termo autorizado pela linguagem da biblioteca, que pode ser encontrada no próprio registro do vocábulo juntamente com as informações sobre a sua utilização.

A Biblioteca A relatou não haver realizado nenhum processo de avaliação da indexação até o momento da coleta de dados, somente pesquisas de alunos de graduação e pós-graduação sobre o tema na biblioteca e que não havia planos para a realização desse procedimento.

Em entrevista retrospectiva realizada na Biblioteca $B$, a equipe demonstrou preocupação com a influência do serviço de referência na análise de assunto e tradução da linguagem natural do usuário para a do vocabulário controlado do sistema, pois é desconhecido para o usuário e, portanto não há compatibilidade entre ambos. Tal preocupação demonstra que o vocabulário controlado talvez não esteja atendendo à sua função primordial, a de servir como instrumento mediador entre a linguagem do usuário e a do acervo. A esse respeito, indica-se a necessidade de estar disponível para consulta do usuário junto à interface de busca do catálogo.

Quanto à linguagem utilizada para a inclusão de termos novos, segundo o catalogador da Biblioteca C, é necessário uma consulta à Library of Congress Subject Headings (LCSH) e, quando o termo não é localizado, recomenda-se consultar a especialista da área após pesquisa do termo e sua conceituação. Para confirmar a inclusão, é necessária a validação do termo por um grupo específico de trabalho.

Foi relatado ao observador pela Biblioteca D que, caso necessário, a linguagem da instituição encontra-se aberta a alterações e atualizações por meio de correção de termos e/ou inserção de vocábulos novos quando não se adequar às necessidades de uso. Também foi verificado pelos relatos que a linguagem está internalizada pela equipe, e que, durante a análise do documento, consegue prever se os conceitos observados são contemplados por termos da linguagem adotada.

Pela observação participante, na Biblioteca D, a política de indexação era desconhecida de parte da equipe. A consequência desse fato pode ser observada na realização da indexação nessa instituição, onde ressaltam-se as características individuais na abordagem do documento. Percebe-se que, por não haver contato com a forma correta de realizar a indexação de acordo com os parâmetros institucionais, o profissional, ao longo do tempo, desenvolve sua forma própria de fazê-lo, gerando resultados díspares para a indexação.

\section{Conclusão}

A política de indexação é um instrumento muito útil em uma biblioteca por buscar soluções para questões como a recuperação por assunto, melhorando sua visibilidade perante o usuário. A disponibilização on line dos catálogos traz visibilidade ao sistema de recuperação da informação, o que exige do bibliotecário uma nova postura, responsável e comprometida com a realidade de uma comunidade potencial de usuários cada vez maior e mais exigente quanto aos serviços de que neces-sita. Por ser esse catálogo a principal ferramenta de acesso aos documentos de uma biblioteca, torna-se justificável a definição de uma política de indexação.

É essa política que, ao orientar, compor estratégias e instrumentar a ação para representar a informação e as necessidades dos usuários, atende à racionalização e à objetividade que a prática profissional requer, minimizando a subjetividade característica dessa atividade e, com isso, aprimorarando à recuperação da informação.

Formalizar os procedimentos de indexação, mesmo que seja a decisão de realizá-la com a definição de 
diretrizes básicas a serem observadas, não implica custo extra às bibliotecas, tanto no que diz respeito aos seus recursos materiais e financeiros quanto ao humano. Pelo contrário. A racionalização dos procedimentos resultará em economia futura desses mesmos recursos.

A Biblioteconomia tem a possibilidade, por meio do desenvolvimento de políticas e manuais de procedimentos, de transformar estratégias em conhecimento explícito da organização. Formalizar decisões em documentos que funcionem como guias a outros funcionários que possam fazer parte da equipe de trabalho e que permitam a melhor visualização das etapas de um processo, aqui o de indexação, permitindo a sua avaliação, é procedimento válido e urgente nas instituições.

Quanto à metodologia, pode-se concluir que há a possibilidade de uso da pesquisa participante nas bibliotecas, porém se faz necessária a ampliação de estudos a esse respeito para minimizar as dificuldades possíveis, em razão da não existência de modelos apropriados à ambiência escolhida como objeto.

Pôde-se perceber que o processo de indexação é realizado em todas as instituições observadas, ainda que com deficiências quanto a critérios de execução e, em especial, quanto a programas de avaliação dos resultados do procedimento. Desse modo, sugere-se a ampliação dos estudos na temática da avaliação da indexação, com vistas a incentivar a realização desses proce-

\section{Referências}

Almeida, M.C.B. Planejamento de bibliotecas e serviços de informação. Brasília: Briquet de Lemos, 2000.

Alvares Júnior, L.; Saldanha, G.S. O mundo é o assunto: epistemologia da indexação no século XIX. In: Ribeiro, F.; Cerveira, M.E. (Org.). Informação e/ou conhecimento: as duas faces de Jano. Portugal: ISKO, 2013. p.81-90.

Araújo, E.P.O.;Paula, C.P.A. Dimensões subjetivas no tratamento da informação: analisando o processo de indexação e implicações subjacentes na recuperação da informação. In: Encontro Nacional de Pesquisa em Ciência da Informação, 15., 2014, Belo Horizonte. Anais... Belo Horizonte: UFMG, 2014. p.702-719.

Carneiro, M.V. Diretrizes para uma política de indexação. Revista da Escola de Biblioteconomia da UFMG, v.14, n.2, p.221-241, 1985.

Foskett, A.C. A abordagem temática da informação. São Paulo: Polígono, 1973. dimentos em unidades de informação em bibliotecas universitárias.

Finalmente, a contribuição do estudo diagnóstico é a determinação de estágios de política de indexação em bibliotecas universitárias e a indicação dos problemas e possíveis encaminhamentos de solução, passíveis de orientar profissionais e pesquisadores na condução de estudos sobre política de indexação. Quanto ao estudo analítico, a contribuição consiste na metodologia de pesquisa participante com a proposição e a aplicação de um roteiro de observação participante com uso de entrevista, coleta e análise de documentação, protocolo verbal e entrevista retrospectiva. Os resultados obtidos revelam o contexto sociocultural do catalogador que realiza a indexação na biblioteca universitária e, sobretudo, seu envolvimento com a política de indexação.

\section{Agradecimentos}

Ao Conselho Nacional de Desenvolvimento Científico e Tecnológico (Processo 305648/2009-8).

\section{Colaboradores}

Todos os autores contribuíram na concepção e desenho do estudo, análise de dados e redação final.

Fujita, M.S.L. A identificação de conceitos no processo de análise de assunto para indexação. Revista Digital de Biblioteconomia e Ciência da Informação, v. 1, n.1, p.60-90, 2003. Disponível em: <http://www.sbu.unicamp.br/seer/ojs/viewissue. php?id=1>. Acesso em: 4 jun. 2010.

Fujita, M.S.L. Política de indexação para bibliotecas. Marília: Unesp, 2010.

Fujita, M.S.L. A política de indexação para representação e recuperação da informação. In: Gil Leiva, l.; Fujita, M.S.L. (Org.). Política de indexação. São Paulo: Cultura Acadêmica, 2012. p.17-28.

Gil Leiva, I. Manual de indización. Gijón: Trea, 2008.

Guimarães, J.A.C. As políticas de indexação como elemento para a gestão do conhecimento nas organizações. In: Vidotti, S.A.G. (Org.). Tecnologias e conteúdos informacionais. São Paulo: Polis, 2004. p.43-52.

Guinchat, C.; Menou, M. Introdução geral às ciências e técnicas da informação e documentação. 2.ed. Brasília: Ibict, 1994. 
Hjørland, B. Fundamentals of knowledge organization. International Society for Knowledge Organization, v.30, n.2, p.87-111, 2003

Lancaster, F.W.; Gallup, E. Information retrieval on-line. New York: Special Libraries Association, 1973.

Lancaster, F.W. Avaliação de serviços de bibliotecas. Brasília: Briquet de Lemos, 1996.

Lancaster, F.W. Indexação e resumos: teoria e prática. 2.ed. Brasília: Briquet de Lemos, 2004.

Olson, H.A.; Boll, J. Subject analysis in online catalogs. 2.ed. Englewood: Libraries Unlimited, 2001.
Rubi, M.P. Política de indexação para construção de catálogos coletivos em bibliotecas universitárias. 2008. Tese (Doutorado em Ciência da Informação) - Faculdade de Filosofia e Ciências, Universidade Estadual Paulista, Marília, 2008.

Vickery, B.C. Analysis of information. In: Kent, A., Lancour, H. (Ed.). Encyclopedia of library and information science. New York: Decker, 1968. v.1, p.355-384.

World Information System for Science and Technology. Princípios de indexação. Revista da Escola de Biblioteconomia da UFMG, v.10, n.1, p.83-94, 1981. 
Projeto de Pesquisa: "Política de indexação para bibliotecas" (bolsa Produtividade em Pesquisa CNPq nível 1C)

Autora: Mariângela Spotti Lopes Fujita (Professora Titular do Departamento de Ciência da Informação da Faculdade de Filosofia e Ciências da Universidade Estadual Paulista "Júlio de Mesquita Filho" - Campus de Marília).

Proposição: sistematizar uma proposta teórica e metodológica de elaboração de política de indexação com e para bibliotecas.

Objetivos da aplicação do questionário: coleta de dados em bibliotecas públicas e universitárias da região Sudeste do Brasil para análise de metodologias e experiências de elaboração de política de indexação e manuais de indexação.

\begin{tabular}{|ll|}
\hline Cidade/Estado & Biblioteca/Instituição \\
\hline Diretor/a ou bibliotecário responsável & Dados contato:(email, telefone, endereço) \\
\hline Data de preenchimento
\end{tabular}

\section{Dados Gerais:}

1. Breve histórico da instituição:

2. Áreas de assunto cobertas pela coleção:

3. Especificar quantidade de profissionais da biblioteca e formação exigida:

4. Número de profissionais dedicados a tarefas de indexação ou catalogação de assuntos:

5. Os Indexadores/catalogadores recebem cursos específicos sobre indexação/catalogação de assuntos quando começam com essa tarefa?

( ) Sim. Tipo de curso, duração, etc:

( ) Não

6. Os Indexadores/catalogadores recebem formação contínua?

( ) Sim. Tipo, duração, etc:

( ) Não

\section{Prática de Indexação ou catalogação de assunto}

7. Realizam a indexação de documentos/catalogação de assuntos a partir de registros copiados de algum catálogo ou banco de dados? Não ( )

$\operatorname{sim}($ )

7.1 Se realizam a indexação/catalogação de assuntos de registros copiados de algum catálogo ou banco de dados informar a fonte:

8. A instituição dispõe de uma política de indexação regulamentada?

( ) Não

( ) Sim. Foi publicada ou está disponível para consulta pela equipe?

9. Você dispõe de um manual de procedimentos para a indexação/catalogação de assuntos?

( ) Sim. Comentar. Foi publicado ou está disponível para consulta pela equipe? Não foi publicado, mas está disponível para catalogadores na rede interna?

( ) Não

10. Durante o processo de indexação/catalogação de assuntos é utilizado algum auxílio automático ou semi-automático para facilitar essa operação?

( ) Sim. Listar e descrever:

( ) Não

\section{Qualidades da indexação}

Responder mesmo que as decisões não estejam descritas em um documento.

11. O grau de especificidade na indexação/catalogação de assuntos está estabelecido?

( ) Sim. Qual?
( ) Não 
12. Existe indicação sobre o número de termos/assuntos por documento?

( ) Sim. Qual?

( ) Não

13. Há indicação de tempo dedicado a esse processo?

( ) Sim. Qual?

( ) Não

14. Segue alguma norma nacional ou internacional para a indexação/catalogação de assuntos?

( ) Sim. Qual?

( ) Não

15. Tudo isso está contido em algum documento? (Política de indexação, manual de serviços, roteiro de procedimentos, etc.)

( ) Sim. Qual?

( ) Não

\section{Ferramentas para a indexação ou catalogação de assuntos}

16. Utilizam algum sistema de validação/correção automática de termos/assuntos para garantir a consistência no catálogo/banco de dados? ( ) Sim. Descrever: lista de autoridades tanto de assuntos como de nomes (geográficos, nomes de pessoas, identificadores, séries e títulos). ( ) Não

17. Utilizam termos/assuntos sem controle de vocabulário, isto é, em linguagem natural (MARC21 653)?

( ) Sim.

( ) Não.

Descrever e enumerar as linguagens de indexação utilizadas.

( ) Lista de cabeçalho de assunto. Qual?

( ) Tesauro. Qual?

( ) Outros. Qual?

18. Participam ou participaram de projetos de compatibilidade/interoperabilidade de vocabulários controlados?

( ) Sim. Listar e descrever:

( ) Não

\section{Avaliação da indexação ou catalogação de assuntos}

19. Realizaram algum tipo de testes ou ensaio para a avaliação periódica da prática de indexação/catalogação de assuntos?

( ) Sim. De que tipo?

( ) Não

20. Existem relatórios publicados ou públicos dessa avaliação?

( ) Sim. Listar e descrever:

( ) Não

\section{COMENTÁRIOS:}


